\section{La imagen teatral. Cartografías del cuerpo como presencia en la realización escénica}

\author{
Nicolás Perrone \\ Universidad Nacional de Cuyo, Argentina \\ luisnicolasperrone@gmail.com
}

Fecha de recepción: 22/02/2019. Fecha de aceptación: 20/04/2019.

\section{Resumen}

La posibilidad de una modulación sobre la imagen y el concepto de imagen se efectúa en numerosas prácticas teatrales contemporáneas que ponen en evidencia un trabajo de quiebre sobre la noción de representación. En ellas se aprecia una presencia particular de las corporalidades, que constituye una cartografía en la que se entraman conceptos y experimentaciones desde/sobre los cuerpos. Desde esta perspectiva intentaremos proponer y fundamentar el concepto de imagen-teatral, partiendo de algunas categorías deleuzianas y atendiendo a sus derivas. La performance de los cuerpos en escena constituye un modo de presencia peculiar que bien puede entenderse como imagen. Pero una imagen teatral no estaría capturada por la lógica identitaria de la representación, sino que, más bien, abre el horizonte hacia otra lógica, en cuyo seno se suscitan una serie de fuerzas que se definen en su realización, así como también lo hacen la intervención de lo visible, lo sonoro, lo táctil, en relaciones descentradas. En este sentido, el carácter performático de ciertas prácticas teatrales es crucial para entender la imagen-cuerpo. En este artículo intentaremos conjugar estos conceptos, considerando como referencia algunas obras experimentales recientes: Un des-generado en el claro de luna (Gires Escénicas, La Rioja. 2017) y Bajorrelieve apocalíptico (Los Toritos, Mendoza, 2018).

\section{The Theatrical Image. Cartographies of the Body as Presence in the Scenic Realization}

\begin{abstract}
The possibility of a modulation on the image and on the concept of image is displayed in the numerous contemporary theatrical practices that question the traditional notion of representation. The particular presence of corporalities that can be identified in them may be approached as a cartography that articulates and presents different concepts and experimentations through / on the bodies. From
\end{abstract}

Palabras clave

Imagen teatral cuerpo performance Un des-generado en el claro de luna

Bajorrelieve apocalíptico
Keywords

Theatrical Image Body Performance

Un des-generado en el claro de luna

Bajorrelieve apocalíptico 
this perspective, we will try to propose and base the concept of theatrical image, starting from some Deleuzian categories and following their drifts. The performance of the bodies on stage constitutes a peculiar mode of presence that can be understood as an image. However, a theatrical image is not captured by the logic of representation. Instead, it opens the horizon towards another logic, which hosts a series of forces that are defined in its realization, just as other dimensions -like the intervention of the visible, the sonorous, the tactile- do as well, in off-center relationships. The performative character of certain theatrical practices is, therefore, crucial to understand the body-image (imagen-cuerpo). In this essay we will try to combine these concepts, considering as a reference some recent experimental plays: Un des-generado en el claro de luna (Gires Escénicas, La Rioja. 2017) and Bajorrelieve apocalíptico (Los Toritos, Mendoza, 2018).

\section{Introducción}

La posibilidad de producir una modulación sobre el concepto de imagen que habilite a pensar las prácticas teatrales se vislumbra como alternativa si ponemos el foco sobre los cuerpos que aparecen en escena y la manera en que se trabaja su presencia. Para ello, requerimos de una constelación de categorías que permitan producir una ampliación de la noción de imagen y, a la vez, funcionen como marco epistemológico para pensar las corporalidades del teatro desde esa perspectiva y de su performatividad. Esta problematización se apoya en la hipótesis de que la corporalidad es el territorio de la imagen en el teatro; la imagen teatral no es ya una representación, sino una presencia material que se define hic et nunc. No la entendemos como ilustración, reproducción o imitación, sino como producción de materialidades descentradas. Por lo tanto, nuestro enfoque de análisis se ubica del lado de las prácticas teatrales que indagan sobre la experimentación acerca de la corporalidad que se pone en escena.

Desde inicios del siglo XX, pero sobre todo a mediados del mismo, las realizaciones escénicas se han desenvuelto en una variedad muy disímil de búsquedas y reflexiones sobre el hecho teatral. A partir de que Stanilavski anunciara la necesidad del trabajo del actor sobre sí mismo, hemos asistido a una pluralidad de indagaciones sobre la escena que se separan de las técnicas tradicionales, cuyo marco de referencia era la interpretación mimética. Con los aportes de maestros como Meyerhold y Grotowski, por solo mencionar algunos, hasta las prácticas de la performance contemporáneas, es posible identificar una preocupación de replantear los esquemas del hecho teatral en función de una puesta en foco del cuerpo como el territorio propio de la teatralidad. Meyerhold, por ejemplo, propone un tipo de trabajo biomecánico, en el cual el actor es creador de formas plásticas a partir del conocimiento de la mecánica de su propio cuerpo: el ritmo, el equilibrio, el movimiento son partes orgánicas de la actuación y se efectúan comenzando por el simple entrenamiento físico. Por su parte, Grotowski plantea la idea de un teatro pobre, refiriendo una especie de operación sustractiva; esta consiste en la eliminación de todos los elementos que pueden ser prescindibles para el desarrollo del hecho teatral (vestuario, escenografía, la misma sala teatral, etc.). De este modo, llega a la conclusión de que el cuerpo del actor es el único elemento sin el cual el teatro no podría existir; por lo tanto, su investigación se orienta a una potenciación de las posibilidades compositivas de ese cuerpo. Esto tiene, incluso, antecedentes en la obra de Antonin Artaud, quien cuestionó la lógica representativa del teatro durante la primera mitad del siglo XX. Su propuesta de un teatro de la crueldad se dirige a una destrucción de la imitación, a una reconfiguración de los órganos y a una abolición de la distancia entre el actor y espectador, dejando circular los flujos vitales en un intento de recuperación del rito como locus originario del teatro; todo 
ello produce una clausura de la representación, que tiene sus ecos en las prácticas teatrales y performativas contemporáneas. En las últimas décadas, el trabajo de Bob Wilson, por ejemplo, muestra un interés de configuración de la escena a partir de la plástica. El dispositivo visual de sus producciones hace énfasis sobre la composición escenográfica y el uso de la luz de manera no ilustrativa, sino puramente plástica. Asimismo, la práctica de la performance deja en evidencia que la realización escénica se define por su operación. En ella se ponen cuerpos como presencias y lo definitorio es la misma experiencia de materialidad que ocurre in situ. En consecuencia, vemos que el decurso que han transitado las teatralidades no deja de problematizar la categoría de representación y de poner sobre la superficie la presencia de los cuerpos.

Este conocido contexto funciona como anclaje de las investigaciones de numerosos grupos independientes dentro de las provincias de Argentina. Las expresiones teatrales que es posible encontrar en ellas cubren un abanico muy amplio de poéticas. Aquí nos interesa pensar acerca de aquellas que asumen un trabajo de experimentación sobre las corporalidades que se ponen en escena. Si bien el término experimental puede abarcar un espectro variopinto de prácticas, aquí estableceremos un recorte de algunas teatralidades que replantean la puesta en escena de los cuerpos.

Entre las numerosas prácticas de experimentación, podemos mencionar algunas obras como El carozo del invierno se llama primavera (2016), del elenco Los Constructores, de Catamarca. En ella se aprecia un trabajo que cuestiona la actuación y su producción discursiva, fragmentando la dramaturgia (se trabaja sólo con algunos versos del poeta proscripto Luis Franco) y recurriendo al balbuceo y la improvisación (actoral y musical) como líneas fuertes de la composición escénica. Otras obras como Panóptico (2002) y Mujeres de Magdala (2005) del elenco Kamar, de La Rioja, ponen en evidencia una búsqueda de un cuerpo político que dé cuenta de algunas problemáticas sociales que preocupan a sus miembros, como los dispositivos de control y disciplinamiento, la opresión sobre las mujeres o sobre otras minorías como los refugiados. Sus dispositivos de visibilidad escénica están influidos por el llamado teatro antropológico y el modo de abordaje que ha realizado Eugenio Barba y su Odin Teatret, con una fuerte impronta de problemáticas latinoamericanas. También podemos mencionar el trabajo del grupo sanjuanino Ob Caenum y obras como Variaciones sobre el polvo I, II, III (2011, 2012, 2013) o Medea Se Sonal (2015). La investigación de este elenco se caracteriza por la constitución de un complejo dispositivo escénico, que funciona como una instalación, en el cual todos los elementos usualmente externos (luz, sonido) son operados desde el interior de la escena. Asimismo, hay una constante hibridación de lenguajes teatrales, performáticos y audiovisuales, con una presencia muy importante de dispositivos técnicos. La compañía mendocina Los Toritos trabaja, en una perspectiva grotowskiana, sobre la búsqueda de un cuerpo extracotidiano a través de una investigación sobre la actuación desvinculada de las técnicas tradicionales y de la representación. En obras como Argentina Infierno 7 (2005) o Hamlet la caja negra (2011) se aprecia un dispositivo escénico de mecanización de los cuerpos, distorsión de la voz y sustracción o despojamiento de elementos escénicos; en otras como Yocasta es una señora irascible (2016) o Bajorrelieve apocalíptico (2018) la realización escénica persiste en el despojo, abandona la mecanización y tiende hacia la hibridación con la danza; todo esto en virtud de la configuración de otras corporalidades.

La lista de obras y elencos podría ser infinitamente más extensa. Pero aquí nos centraremos en dos trabajos: Un des-generado en el claro de luna (Gires Escénicas, La Rioja, 2017) y Bajorrelieve apocalíptico (Los Toritos, Mendoza, 2018). A partir de la singularidad de estas producciones escénicas, pretendemos leer la presencia 
de determinados conceptos que configuran la constelación de la categoría de imagen teatral. La problematización sobre el cuerpo desde un corrimiento de la noción de representación es el punto de referencia sobre el que se apoya una cartografía semejante.

\section{Cuerpo e imagen}

De acuerdo con nuestro planteo, necesitamos pensar la vinculación entre cuerpo e imagen. Pero para que ese vínculo sirva para delinear la categoría de imagen teatral, es preciso desligarlo de la tradicional concepción mimética, la cual suele funcionar como un primer modo de acceso a dicha relación. Tal perspectiva no da cuenta completamente de la presencia material de los cuerpos. Por lo tanto, necesitamos plantear la problemática desde otro interrogante. ¿Es posible pensar la materialidad de los cuerpos como territorio de la imagen? Esta pregunta supone un desplazamiento de la cuestión de la representación, en la medida en que no estamos afirmando esa vinculación simplemente como la ilustración o representación de un cuerpo en una imagen, ni tampoco la reproducción de una imagen en el soporte de un cuerpo. Por el contrario, consideramos que los cuerpos mismos constituyen imágenes como presencias materiales. Esto nos permite deslocalizar la relación cuerpo-imagen del fijismo representacional. La imagen se abre, entonces, hacia otro locus. Como afirma Alejandra Castillo:

Lo propio de la imagen es la indeterminación. Las imágenes se enlazan y desvinculan lo visible y su significación, palabra y efecto produciendo sentidos pero, a su vez, desviándolos. La imagen, entonces, como falla y alteración, como apertura y performance. Lejos de la estabilización, la imagen es la superficie en la que confluyen diversos registros. Lugar de cruces y desfases infinitos en el que se encuentran, en tanto efectos de circulación, objetos, sujetos, lo expresado, lo silente, la intención, así como la falta de ella, el presente y el pasado (Castillo, 2015: 59-60).

El texto de Castillo muestra la posibilidad de pensar un régimen ampliado de la imagen. Su territorio es el de una multiplicidad. En primer lugar, la autora destaca la fisura del sistema semiótico que suele capturar a las imágenes en una lógica unilateral de la significación. Los diversos enlaces producen sentidos, pero también los desvían, es decir, desterritorializan la estabilidad de la imagen. Sus efectos son plurales, por ejemplo, efectos performativos que producen normatividad o bien que la deshacen. Si la imagen se fractura y abre hacia otros registros, entonces podemos suponer que uno de ellos es la materialidad de los cuerpos que hacen presencia en un aquí y ahora. Cuerpos que son ellos mismos imagen.

Lo propio de la teatralidad es la presencia de materialidades; por ello, la imagen teatral se inscribe en las corporalidades que se presentan durante la realización escénica. Es decir que el cuerpo es la superficie de registro de la imagen. Éste ya no es el portador de un sentido a priori; lo visible no se atribuye necesariamente a una significación. Entonces, es claro que la imagen en el teatro, el cuerpo-imagen, se desvía hacia un territorio productivo, donde se da lugar a sentidos heterogéneos. Éstos dependen del modo en que se entrame la realización escénica. Asimismo, en tanto la indeterminación es la propiedad de la imagen, es importante revisar el modo en que las prácticas contemporáneas exploran un desajuste sobre las corporalidades, para indicar que éstas ya no pueden ser capturadas por la forma de una identidad definitiva. En este sentido, los cuerpos se deconstruyen, al modo de un cuerpo sin órganos, para mostrar las posibilidades de otros modos de existencia.

Como mencionamos, el concepto de cuerpo sin órganos ( $\mathrm{CsO}$ ) resulta de particular interés para configurar esta cartografía de cuerpo-imagen. Deleuze toma esta noción 
de Artaud y explica que el CsO es aquel que deshace la organización del organismo. Esto quiere decir que el cuerpo no es opuesto a los órganos, sino a la organización (Deleuze, 2009: 51). Es posible que el cuerpo se corra de las jerarquías que lo configuran con determinada forma y produzca el nacimiento de otro cuerpo. Éste ya no es la imagen de una determinación fija, sino que se define por la presencia temporal o provisoria de órganos indeterminados. Esto quiere decir que el cuerpo no representa nada, sino que es intensivo.

Se trata de hacer un cuerpo sin órganos, allí donde las intensidades pasan y hacen que ya no haya ni yo ni el otro, no en nombre de una mayor generalidad, de una mayor extensión, sino en virtud de singularidades que ya no se pueden llamar personales, de intensidades que ya no se pueden llamar extensivas. El campo de inmanencia no es interior al yo, pero tampoco procede de un yo exterior o de un no-yo. Más bien es como el Afuera absoluto que ya no conoce los Yo, puesto que lo interior y lo exterior forman igualmente parte de la inmanencia en la que han fundido (Deleuze y Guattari, 2010: 161-162).

Como afirman Deleuze y Guattari, el CsO se hace; esto quiere decir que es el resultado de una experimentación, el residuo de la misma. Pero lo realmente interesante es que un $\mathrm{CsO}$, al deshacer la organización del organismo, también se desvincula de la noción de yo e identidad. El fijismo de lo identitario queda diluido en el cruce de intensidades que pasan por un $\mathrm{CsO}$. Estas categorías son útiles para comprender el decurso de las prácticas escénicas que hemos mencionado como objeto de estudio. En ellas, la noción de personaje está generalmente deshecha. Esto permite un corrimiento de la representación tradicional y un desplazamiento hacia lo que, en términos de los autores, es un plano de inmanencia o de composición. Como podemos leer en la cita anterior, el plano de inmanencia no es una interiorización hecha por un yo. La escena, en tanto plano, ya no pasa por un personaje que interiorice las posibilidades de circulación de fuerzas en una estructura cerrada que sería la identidad que representa. Por el contrario, una escena de la inmanencia se dirige hacia un territorio donde el afuera y el adentro ya no son instancias separadas, sino que se fusionan. Como veremos más adelante, los elementos escénicos que otrora eran simples exterioridades ajenas al cuerpo y funcionaban como meros decorados funcionales a la representación, ahora son parte de la imaginería de la obra, esto es, son parte de una nueva forma de corporalidad que intentamos pensar como imagen teatral: la presencia de todos los elementos escénicos son, en verdad, la materialización de un plano de inmanencia que no representa nada, sino que visibiliza una presencia, que constituye un dispositivo de mostración que es, en sí mismo, una imagen.

La noción de $\mathrm{CsO}$, entonces, nos ayuda a entender mejor este nuevo régimen de la imagen y de los dispositivos de visibilidad escénica. Así, pues, los órganos en sí mismos no constituyen un problema que haya que extirpar, sino que, más bien, lo que se torna conflictivo es la fijación y endurecimiento de los mismos, de tal forma que impidan la aparición de otras posibilidades de existencia. El problema es la fijación en una identidad, la representación de una identidad. El cuerpo sin órganos es intensivo, es el territorio por el que circulan diversas fuerzas; lo que hay es una gradualidad de flujos que transitan y no un espacio liso que funcione de soporte a la representación de un organismo. Cada tipo de $\mathrm{CsO}$ implica modos heterogéneos de producción que se suceden sobre un plano. Así, pues, la manera de hacerse el cuerpo es a través de la experimentación, ya que ella permite explorar conexiones inesperadas, liberar líneas de fuga. Deshacer la organización es desterritorializarla, permitir nuevos agenciamientos, nuevas formas de circulación y acoplamiento. 
Esta es la tarea que está de fondo en las investigaciones de la compañía mendocina Los Toritos. La búsqueda de una ruptura con la actuación naturalista apunta a la generación de una serie de agenciamientos maquínicos y de enunciación, que resulten en la producción de un residuo, que es el cuerpo sin órganos. Un cuerpo nuevo, nacido de la singularidad, irreductible, atravesado por intensidades, improductivo en sí mismo, pero con la potencialidad de abrir en el espectador la actividad de producción de sentidos o la posibilidad de verse atravesado por afectos.

El cuerpo sin órganos que aparece en las obras de la compañía no es un cuerpo semiótico que se halle en tensión con un mero cuerpo fenoménico. Es la materialización de una serie de agenciamientos. Por ello, es una imagen teatral, es la presencia de un sistema abierto y, por tanto, desterritorializable. Cuando hablamos de cuerpo semiótico, nos referimos a que éste sea el instrumento con el que se representa un significado, el cual estaría establecido de antemano. Como señala Erika Fischer-Lichte, para emplear el cuerpo de esta forma, "hay que someterlo primero a una cierta descorporización (Entleiblichung): todo lo que remita al cuerpo orgánico del actor, a su físico estar-en-el mundo, debe ser eliminado de él hasta que quede un cuerpo semiótico "puro»" (2014: 162). Desde esta perspectiva, el cuerpo simplemente buscaría los signos adecuados para manifestar significados, despojándose del cuerpo del actor como un cuerpo fenoménico, que está-en-elmundo. La atención se desvía hacia la interpretación del personaje; lo que el espectador debe ver es el personaje y no el sujeto que lo encarna. Sin embargo, esta manera de entender la corporalidad está atada a la autoridad del texto. El actor debe representar el sentido que está previamente establecido por la palabra. Pero desde Artaud en adelante, esta autoridad ha sido desmantelada. El trabajo de investigación de Los Toritos se mantiene en esta línea de desplazamiento. Como dijimos, el cuerpo no es semiótico, sino que funciona como un dispositivo en el que se agencian elementos heteróclitos. Consideramos que este corrimiento es el que permite entenderlo como imagen; una imagen teatral que se justifica en la materialización, que se configura con elementos asignificantes en sí mismos, y se da en las diversas formas en que aparecen en escena los agenciamientos de esos elementos.

La obra Bajorrelieve apocalíptico (Los Toritos, 2018), escrita y dirigida por Daniel Fermani, se ha diagramado a partir de un agenciamiento entre la danza butoh y las técnicas teatrales de desarticulación del cuerpo, que constituyen la peculiaridad de la investigación de la compañía mendocina. En este sentido, la fuerza de la hibridación se abre a un territorio donde la producción de corporalidad se registra en un $\mathrm{CsO}$ que transita por numerosos devenires animales, femeninos, masculinos, monstruosos, inorgánicos, etéreos; en definitiva, de intensidades en movimiento. Por ello, la corporalidad de la obra configura su propio plano de consistencia, al cual se agencian otras

multiplicidades como las de la luz, los elementos de utilería, la música y el canto. Todas ellas diagraman la cartografía que, luego, tendrá la forma de un dispositivo de visibilidad, que es la obra misma. Esta maquinación de heterogeneidades configura una imagen teatral; esto es, la presencia del cuerpo en un montaje que tiene el carácter de un sistema abierto. 


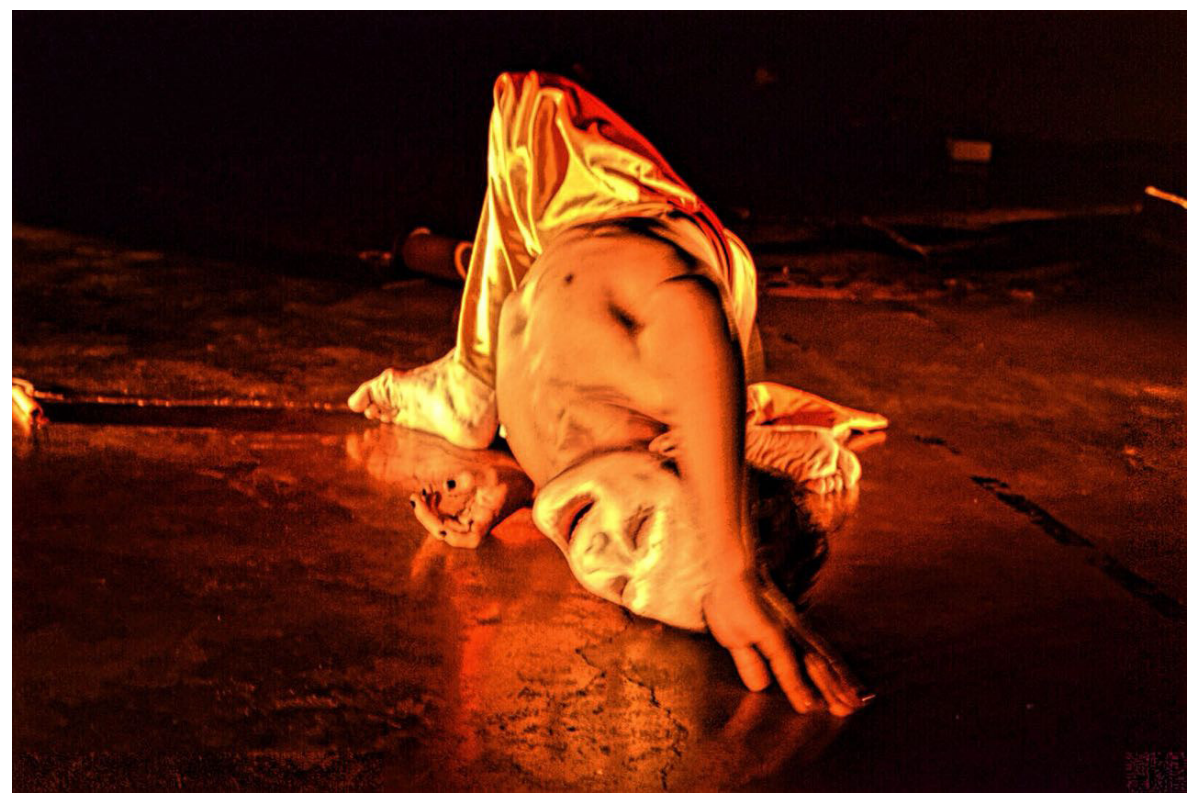

Figura 1. Bajorrelieve apocalíptico. Fotografía de Bernarda Hopp Ansaldi.

El cuerpo, en Bajorrelieve apocalíptico, transita devenires. Siguiendo a Deleuze, entendemos que el devenir es una operación del orden de la alianza; esto quiere decir que "el movimiento ya no se produce por relaciones filiativas, sino por comunicaciones transversales entre poblaciones heterogéneas. (...) Devenir no es ciertamente imitar, ni identificarse; tampoco es regresar-progresar; tampoco es corresponder, instaurar relaciones correspondientes" (Deleuze y Guattari, 2010: 245). Un devenir no imita nada. No se trata, en la actuación, de la construcción de un personaje. No hay término al que se dirija el trabajo del actor, sino más bien una materialización que se define por su operación, por su movimiento, por su mutación, por la alianza de elementos heteróclitos. Hay escenas donde el cuerpo aparentemente se territorializa en la figura de un personaje, como Prometeo o el Minotauro. En realidad, en ellas hay una exploración de flujos animales y monstruosos respectivamente. Hay una superposición de elementos que se agencian y materializan un cuerpo. Por ejemplo, el trabajo sobre la voz recorre diversas distorsiones y tonos, como así también intensidades de volumen. Todo ello tiene un valor asignificante, no representa la palabra. Asimismo, la luz envuelve de manera penumbrosa el cuerpo, generando una imagen donde las sombras pueden recortar los bordes del cuerpo del actor. Tenemos, en consecuencia, dos imágenes superpuestas: la imagen sonora con sus variaciones y la imagen visual del recorte de luz y sombra. Estas imágenes son cuerpo en sí mismas, es decir, son una materialidad que aparece sobre la escena. A ello se acopla el trabajo sobre el cuerpo que realiza el actor. En las escenas mencionadas se transita por unas intensidades microfísicas, las cuales resultan de la exploración con imágenes (propio de cierto abordaje de la danza butoh). Esto no quiere decir que el actor esté representando una imagen, sino que la imagen sirve de punto de anclaje del devenir que transita el cuerpo. Es la búsqueda de una textura, una energía, una vibración localizada, etc., que ponga en movimiento las partes extensivas del cuerpo. Toda esa composición está condensada en movimientos sutiles. Sin embargo, como imagen, persiste en la composición del cuerpo, quizás como una virtualidad. En consecuencia, la imagen teatral, condensa toda esta multiplicidad de trabajos; es la presencia material de dicha multiplicidad. 


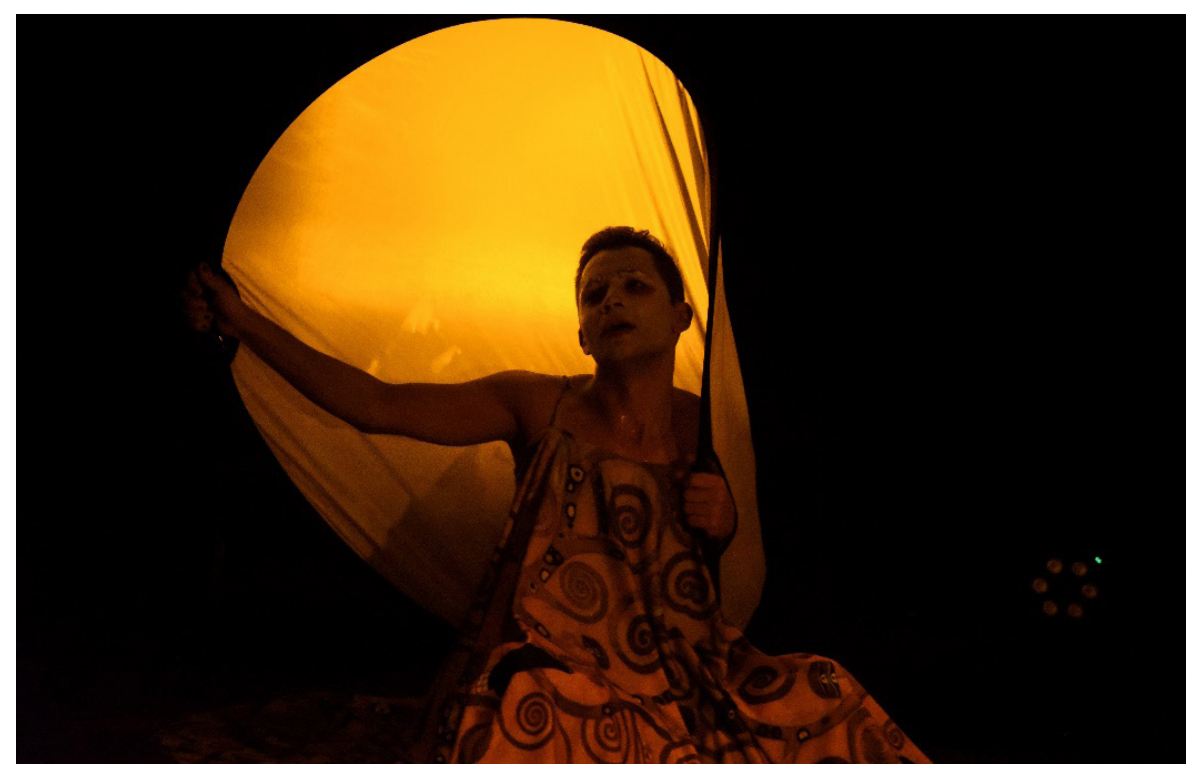

Figura 2. Bajorrelieve apocalíptico. Fotografía de Sabrina Pascual.

Por otra parte, el uso de la utilería y el vestuario no es instrumental. Los escasos elementos empleados se transfiguran en el cuerpo del actor adquieren un acoplamiento orgánico, entendiendo por orgánico no un orden de jerarquía, sino una forma en la que los elementos no son puras exterioridades ajenas; éstos son el cuerpo mismo. Por ejemplo, se emplea una pantalla circular que se encuentra colgada gran parte de la obra, inerte. Cuando el actor la toma, ésta se agencia a su cuerpo y configura otro cuerpo. La visualidad de la escena está en primer plano, aunque lo clave de esto es cómo la experimentación tiende a transfigurar todo en cuerpo. La corporalidad no se limita jamás a la extensión del actor, sino que es un proceso de individuación en conjunto con todos los elementos del plano de composición. En este caso, el agenciamiento está operado por el actor, la pantalla que adquiere diversas formas en su manipulación, la luz que le otorga una calidad específica, las sombras que proyecta, el uso de una tela que muta en vestido y a la vez extiende las extremidades del actor, la palabra que se inserta en toda esta imaginería. En este sentido, vemos que la imagen teatral es la presencia de estos agenciamientos de multiplicidades que, en sí misma y por separado, no tiene ningún valor significante.

En otras escenas, se exploran imágenes auditivas, por medio de sonidos que transforman la respiración en agitación, y ésta en sonoridades guturales, balbuceos, ahogos, etc. Además, el uso intuitivo de instrumentos poco convencionales (arpa de boca, tambor trueno) operan en la producción de sonidos que engendran ambientes e interrupciones en el decurso de la obra, como así también superposiciones. Aquí vemos otro uso de la imagen, pues su materialidad está puesta en lo auditivo; esto hace una presencia teatral fundamental en el plano de composición de la realización escénica, y produce sus propios efectos. En consecuencia, vemos cómo la noción de imagen se modula constantemente, más allá de la mera visualidad. Esto es parte de la imaginería teatral que propone la obra y que configura la heterogeneidad del dispositivo escénico que, si bien es despojado o aparentemente minimalista, está atravesado por gran cantidad de materialidades.

Esta descripción muestra que la cartografía de un cuerpo en escena es un agenciamiento de multiplicidades. Ese agenciamiento está atravesado por modalidades de la imagen y es, en definitiva, un tipo de imagen, imagen-cuerpo. Por ello, consideramos que la imagen teatral es esta constelación de elementos heterogéneos que se agencian en la presencia escénica. La imagen teatral es esa presencia. 
La obra Un des-generado en el claro de luna (Gires Escénica, La Rioja, 2016), dirigida por Federico Tello, combina varios registros que fluctúan entre lo teatral, la danza, la performance y el audiovisual. Esta realización muestra el devenir de un cuerpo drag queen que se mueve desde la presencia de una masculinidad marcadamente binaria hacia un flujo femenino que ya no es aprehensible desde esa lógica identitaria. Lo indeterminado, lo grotesco, la exageración, la desnudez de un cuerpo sin identidad, van marcando el acontecer de la obra. El dispositivo escénico desnuda al máximo otro dispositivo: el del cuerpo construido. Sobre el escenario están dispuestos una serie de elementos que serán usados para ejecutar el transformismo en escena (peluca, rellenos, medias, cinta adhesiva, plataformas, vestido, etc.). El performer va transformando su presencia, colocándose, ante la mirada del púbico, todos los implementos que configuran la ficción de su imagen femenina, haciendo explícita la tecnología de este género otro, inaprehensible desde el binarismo. El trabajo con la corporalidad, en este caso, configura una imagen desvinculada de las tecnologías que oponen lo masculino y femenino y se desvía hacia otro registro. Para ello, resulta crucial el uso de suplementos (los propios de la estética drag) que adquieren una función performativa; los suplementos producen aquello que pretenden completar (cfr. Preciado, 2011: 14) y el cuerpo aparece como una construcción prostética.

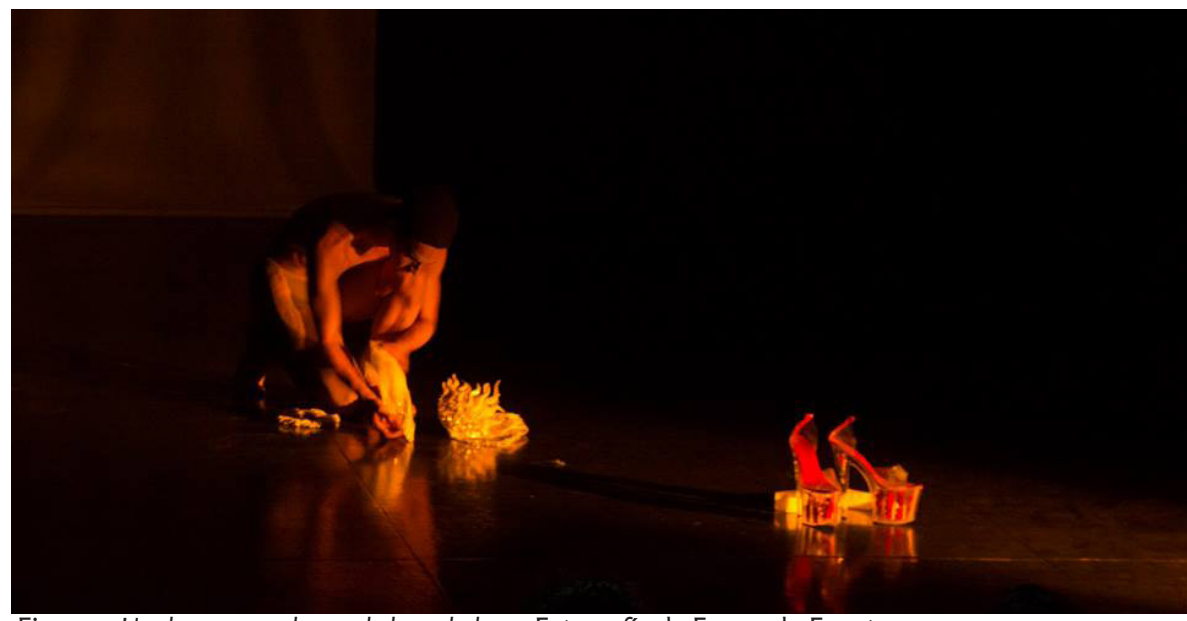

Figura 3. Un des-generado en el claro de luna. Fotografía de Fernando Fuentes.

Este ejercicio de reprogramación genérica muestra in situ una imagen teatral, en cuyo seno nos encontramos con un desmantelamiento del dispositivo escénico, con una performance que deshace la identidad y transita hacia un territorio más indeterminado; en definitiva, con una realización que hace real un cuerpo en tanto lo pone en escena. Lo performativo configura como realidad aquello que realiza. El cuerpo que observamos va jugando constantemente con la construcción y deconstrucción de una corporalidad sexuada, al punto que ésta deviene indefinida, al menos desde la lógica de la representación. Este vaivén se aprecia en las apariciones del cuerpo marcadamente masculino, que luego deviene drag queen, y nuevamente se desarma en otro cuerpo a medio camino entre lo masculino y femenino binario, hasta reaparecer, en la escena final, nuevamente como drag, exhibiendo un vestuario y tocado suntuosos que desestabilizan la visión por su exotismo. Estos ejercicios de desterritorialización son los propios de un $\mathrm{CsO}$, que se instala provisoriamente en un estrato, indaga sus posibilidades y se fuga hacia otro. Pero más preciso sería decir que se instala en un registro contrasexual. Como explica Preciado, "la contrasexualidad no es la creación de una nueva naturaleza, sino más bien el fin de la Naturaleza como orden que legitima la sujeción de unos cuerpos a otros" (2011:12-13). En este caso, se vuelve imposible la aprehensión dentro de una identidad definida, la lógica del binarismo se desmantela y la imagen que presentifica la realización escénica es la de un cuerpo que transita 
por figuras que no son las de una naturaleza previa y, por ello, funciona como un dispositivo de crítica política hacia la sujeción de los cuerpos, hacia el ordenamiento de los mismos. El cuerpo aparece claramente como una tecnología, la cual es dejada al desnudo por la imaginería de la obra.

Muchas de las escenas de esta realización escénica muestran la imposibilidad de capturar el cuerpo como totalidad. Para ello, apela a estrategias de parcialización de la corporalidad a través del uso de proyecciones. En una de ellas, por ejemplo, la imagen se focaliza sobre la piel, impidiendo distinguir de qué parte del cuerpo se trata. La cámara recorre esta superficie, haciéndola aparecer como un espacio indeterminado y material. O bien se enfoca un objeto parcial más determinado, como una mano, que luego es reproducido sobre la escena por medio de la aparición del cuerpo del performer entre el proyector y la pantalla. Se suscita una transición en las imágenes proyectadas desde un espacio puramente indeterminado como la piel, hacia partes extensivas del cuerpo, parcializadas, y finalmente, estas imágenes que aparecían sólo en el registro audiovisual, cobran materialidad en la escena cuando, entre el recorte producido por la luz, comienza a verse un brazo que juega con su existencia parcial y fragmentada. El recorrido por estas parcialidades corporales se desvía de la pura superficie de la piel cuando la proyección comienza a reproducir imágenes del aparato digestivo, mostrando el revés de la trama corporal. En estas imágenes audiovisuales, se indaga el cuerpo como cavidad. Lo que resalta es aquello que no es visible en el cuerpo, los recovecos internos. Aquí es otro órgano el que se pone en primer plano, de manera provisoria. Por lo tanto, la organización del organismo se redistribuye. Lo que resulta llamativo, es que todas esas imágenes parecen remitir a un órgano anal. Recordando a Preciado, "el ano constituye un espacio de trabajo tecnológico; es una fábrica de reelaboración del cuerpo contrasexual poshumano" (2011:24). En consecuencia, la estrategia del audiovisual desde esta perspectiva anal, funciona como un territorio donde se puede visibilizar otro cuerpo; la imagen se vuelve teatralidad. Todo el dispositivo de visibilidad descentra el registro de construcción del cuerpo, hace aparecer un cuerpo sin órganos, una mostración de lo otro del cuerpo. No hay un foco neurálgico, hay multiplicidad de ellos. Aparece una presencia desterritorializada del cuerpo, una performance que configura la materialidad de la imagen teatral.

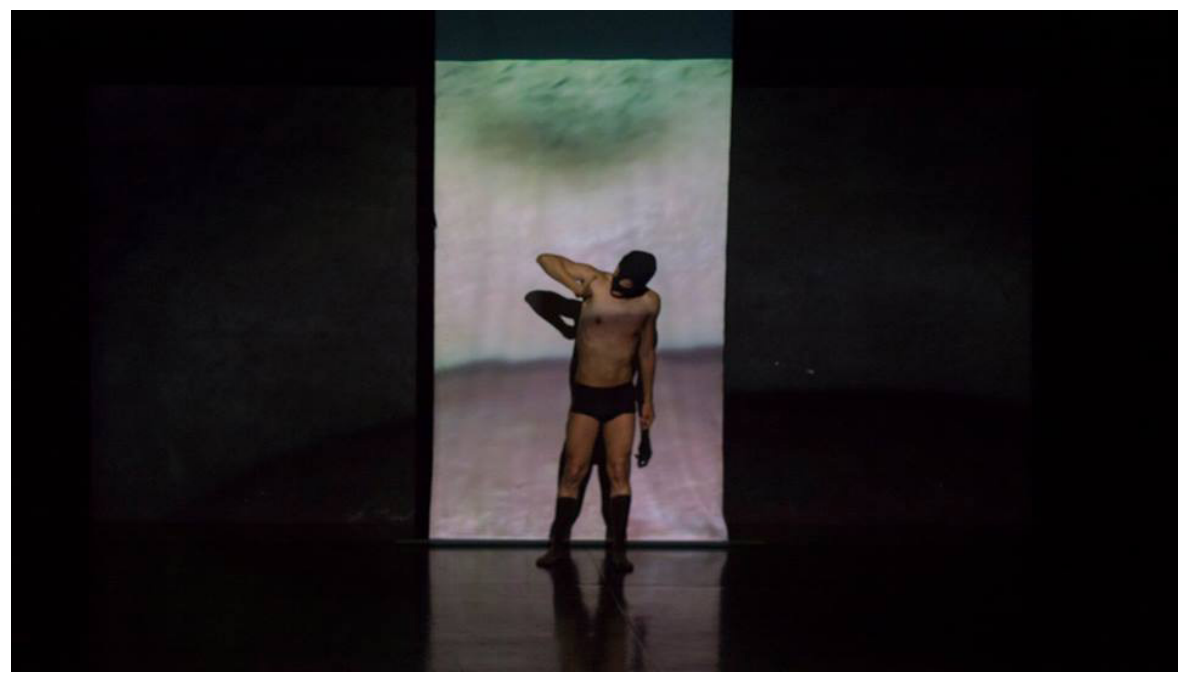

Figura 4. Un des-generado en el claro de luna. Fotografía de Fernando Fuentes.

A la fragmentación visual se suma otra auditiva, el sonido como otro tipo de imagen. Por ejemplo, en una de las acciones, la oscuridad satura toda la escena; entonces una voz en off habla, hace presencia; escuchamos un interrogante sobre lo que puede ser 
el cuerpo, sus agujeros, sus superficies, su no identidad. Las palabras no se corresponden con la acción, ni la describen. Ya no hay acción y la visualidad es casi nula. El aparato ocularcentrista se fisura. La oscuridad pone en primer plano la imagen auditiva, y ésta no tiene un referente visual. Son superposiciones, nuevas imágenes, auditivas en este caso, que aparecen en el agenciamiento de la maquinaria escénica. Este es otro caso del funcionamiento de lo que llamamos imagen teatral.

Hemos presentado algunos de los elementos de la imaginería que proponen las obras en consideración. Si bien los dispositivos de visibilidad de las dos realizaciones escénicas son disímiles, hay operaciones que se podrían considerar comunes. Los agenciamientos de imágenes-cuerpo ponen de relieve el aspecto performativo de la imagen teatral. Aquí queremos decir que la teatralidad se define por su carácter de acontecimiento, por su singularidad y por el desajuste de los cuerpos. Esto implica una suerte de autorreferencialidad y constitución de realidad desde la misma realización escénica (Fischer-Lichte, 2014: 55). Lo que cuenta son los cuerpos en tanto materialidades presentes. Éstos no tienen un referente determinado porque no están pretendiendo representar algo, sino hacer valer en sí la presencia material. De este modo, los cuerpos producen la realidad que presentan y eso es lo que define la realización escénica y su performatividad. El plano de composición comprende imágenes heterogéneas que atraviesan los cuerpos, ya no organizados desde la lógica de la identidad y su representación.

En las dos realizaciones, la imposibilidad de representar está dada, también, por la preocupación de abordar algo irrepresentable. El cuerpo es el territorio que indaga ese irrepresentable. En el caso de Undes-generado en el claro de luna, lo que se quiebra es la representación de cierto cuerpo atravesado por el género binario y la búsqueda de otra corporalidad por fuera de los cánones de la lógica de la identidad. En Bajorrelieve apocalíptico, lo que se violenta es la representación del cuerpo cotidiano ante un contexto que pretende capturarlo en la rigidez de una identidad que anula otros modos de existencia. La búsqueda, en ambos, es la de una corporalidad divergente, la configuración de una imagen que desarticule el cuerpo, el registro de un cuerpo sin órganos o el devenir de flujos heterogéneos. Ya no hay una organización de la escena desde la autoridad de un texto o desde la pretensión de componer un personaje que sería la imitación de una formación hegemónica, esto es, una representación de una identidad. La ilustración de un discurso podría considerarse como una configuración de poder, que ha sido la predominante en las prácticas teatrales hasta las experimentaciones disruptivas que efectúan los teatristas del siglo XX mencionados al comienzo de este escrito. La experimentación permite un desplazamiento de esos centros y la configuración de una cartografía del cuerpo, que es singular en la búsqueda de cada uno de los hacedores teatrales. Esto es importante en la medida en que genera una transformación radical de lo teatral. Como expresa el mismo Gilles Deleuze, al "amputar los elementos de poder, no solamente cambia la materia teatral, sino también la forma del teatro, que deja de ser «representación», al mismo tiempo que el actor deja de ser actor" (2003: 81). Tenemos, más bien, cuerpos que mutan, presencias que hacen efectiva una determinada materialidad.

Asimismo, en el marco de este corrimiento de la representación, ambas producciones comparten una operación que Deleuze llama sustracción. Esta consiste en la mutilación de esos centros de poder mencionados en favor de una comprensión de la realización escénica como operación, como devenir; "el teatro como operación implica sustraer algo de la obra, de tal manera que ese procedimiento, en tanto creador, transforme los tiempos, los objetos, las acciones y por supuesto a los actores" (Etchegaray et al, 2016: 146). Estamos hablando de un nuevo reparto de lo sensible, tomando la expresión de Rancière. No quiere decir que se destituya definitivamente la presencia del vestuario, utilería, texto o iluminación, sino que se transfigura el lugar 
común, son sustraídos como elementos que representen algo. Más bien se articulan como superposiciones. Funcionan como suplementos en la constitución del cuerpoimagen. En este sentido, cambia completamente la cartografía de la escena y la distribución de lo sensible; son partículas asignificantes que componen agenciamientos en la presencia de la realización escénica.

\section{Conclusión}

Hemos indagado sobre conceptos y prácticas teatrales que se corren de la noción de representación en tanto mímesis. En ese marco, la categoría de imagen teatral surge de la problematización de la corporalidad y constituye una modalidad de la imagen que funciona para pensar ciertas teatralidades.

A partir de un régimen ampliado de la imagen, es posible entender que ésta se registra en un cuerpo que, dentro de la realización escénica, explora formas de desajustes de esa misma corporalidad. En esa línea, el concepto de cuerpo sin órganos nos ayuda a pensar algunas teatralidades que experimentan desde y sobre los cuerpos, y quiebran la lógica de la representación. De acuerdo con esto, el trabajo sobre las intensidades, por ejemplo, muestra otros modos de producción de corporalidad. Esas mismas corporalidades funcionan como una imagen. Entendemos, por ello, que la imagen teatral se suscita en la presencia misma de los cuerpos y no se limita a la pura visualidad. También el ámbito de las imágenes sonoras forma parte del régimen de la imagen teatral, pues éstas son materialidades que hacen presencia en la realización escénica.

La imagen teatral es performativa porque produce lo que pretende representar. Más preciso sería decir que no hay una representación en sentido tradicional mimético, sino una producción de la corporalidad. Entonces la performatividad radica en hacer de la imagen una producción corporal. La experimentación tiene el efecto de producir la corporalidad que presentifica como imagen. Por ello, la imagen es presencia y los cuerpos su materialidad inherente.

En las obras abordadas, se muestran cuerpos atravesados por lógicas descentradas, su misma constitución está entramada por una desorganización o desajuste de la identidad. Las imágenes son autorreferenciales, no remiten a otra entidad ajena al propio acontecimiento en que los cuerpos se materializan. No son atribuibles a identidades, sino que se definen por la operación en la que devienen. Abren un espectro de singularidad y de multiplicidad que habilita la intervención activa del espectador en la configuración del sentido. Éste no es algo a decodificar, sino a construir. Por ello, la experimentación permite una redistribución de lo sensible, y la imagen teatral aparece como presencia en ese nuevo reparto. 


\section{Dibliografía}

"Castillo, A. (2015). Imagen, cuerpo. Adrogué: La Cebra

»Deleuze, G. (2003). “Un manifiesto menos”. En: Bene, C. y Deleuze, G. Superposiciones. Buenos Aires: Artes del sur.

》Deleuze, G. (2009). Francis Bacon. Lógica de la sensación. Madrid: Arena

»Deleuze, G. y Guattari, F. (2010). Mil mesetas. Capitalismo y esquizofrenia. Valencia: Pre-textos

"Etchegaray, R. et al. (2016). Acontecimiento y creatividad en la filosofía de Gilles Deleuze. Un nuevo modo de percibir. Buenos Aires: UNLaM, Prometeo.

» Fischer-Lichte, E. (2014). Estética de lo performativo. Madrid: Abda.

》Preciado, P. B. (2011). Manifiesto contrasexual. Barcelona: Anagrama 